\title{
Controlled comparison of nefazodone and amitriptyline in major depressive inpatients
} \author{
Myriam Van Moffaert ${ }^{10}$, Emilie Vanbrabant ${ }^{1}$ \\ ${ }^{1}$ Psychiatric Unit, C.H.U. du Sart Tilman, B-4000 Liège, Belgium \\ ${ }^{2}$ Centre Hospitalier de Sainte-Ode, B-6680 Sainte-Ode, Belgium \\ ${ }^{3}$ Clinique Sainte-Thèrèse, B-6061 Montignies-sur-Sambre, Belgium \\ ${ }^{4}$ Hôpital du Petit Bourgogne, B-4000 Liège, Belgium \\ ${ }^{5}$ Sint-Camillus Hospital, B-9051 Sint-Denijs-Westrem, Belgium \\ ${ }^{6}$ Psychiatrische Centra Sleidinge, B-9940 Evergem-Sleidinge, Belgium \\ ${ }^{7}$ Kliniek van de Alexian Broeders, B-3740 Munsterbilzen, Belgium \\ ${ }^{8}$ Centre Hospitalier Vésale, B-6110 Montigny-le-Tilleul, Belgium \\ ${ }^{9}$ Clinique Saint Vincent, B-4000 Rocourt, Belgium \\ ${ }^{10}$ Universitair Ziekenhuis, B-9000 Gent, Belgium
}

Marc Ansseau ${ }^{1}$, Philippe Darimont ${ }^{2}$, Arlette Lecoq ${ }^{2}$, André De Nayer ${ }^{3}$, Jean-Luc Evrard ${ }^{3}$, Pierre Krémer ${ }^{3}$, Jean-Michel Devoitille ${ }^{4}$, Michel Dierick ${ }^{5}$, Claudine Mertens ${ }^{6}$, Frans Mesotten ${ }^{7}$, Jean Mirel ${ }^{8}$, Benoît Troisfontaines ${ }^{9}$,

Received: 5 February 1993 / Final version: 17 November 1993

\begin{abstract}
Nefazodone, a phenylpiperazine antidepressant, exhibits novel dual activity on serotonin (5-HT) neurons; it binds to $5-\mathrm{HT}_{2}$ receptors and inhibits $5-\mathrm{HT}$ reuptake. Flexible doses of nefazodone (100-400 $\mathrm{mg} /$ day) and amitriptyline (50-200 mg/day) were compared in 106 major depressive inpatients in a 6-week double-blind study. Results showed significant superiority of amitriptyline over nefazodone on all rating instruments: Montgomery and Asberg depression rating scale $(P<0.0001)$, Hamilton depression scale $(P<0.0006)$, Clinical Global Impressions $(P<0.0001)$ and Patient Global Assessment $(P<0.01)$. A total of $65 \%$ of patients under amitriptyline and $56 \%$ of patients under nefazodone reported adverse events during the study, with significantly more dry mouth in the amitriptyline group ( $39 \%$ versus $11 \%$, $P=0.001$ ). Modal daily doses within the last treatment week reached $242 \mathrm{mg}$ with nefazodone and $124 \mathrm{mg}$ with amitriptyline. The lower efficacy of nefazodone, which contradicts comparative trials with imipramine in US patients, is discussed with regard to the dose of nefazodone, probably below the optimal therapeutic range for melancholic patients, and to the clinical differences between the patient samples.
\end{abstract}

Key words: Nefazodone - Amitriptyline - Antidepressant - Major depression

Nefazodone is a chemical and pharmacological analogue of trazodone and a member of the phenylpiperazine class

Correspondence to: M. Ansseau of antidepressants. The pharmacological profile of nefazodone resembles trazodone but is clearly distinct from other antidepressants. Nefazodone exhibits novel dual activity on serotonin (5-HT) neurons: it binds with selectivity and high affinity to central $5-\mathrm{HT}_{2}$ receptors on the one hand and inhibits cortical 5-HT reuptake on the other hand (Eison et al. 1990). Chronic treatment with nefazodone downregulates cortical $5-\mathrm{HT}_{2}$ receptors and results in a dose-dependent reduction in 5 - $\mathrm{HT}_{2}$-mediated behavioral responses while enhancing $5-\mathrm{HT}_{1 \mathrm{~A}}$-mediated neurotransmission, thereby increasing serotonergic neurotransmission (Andrade and Nicoll 1987; Eison et al. 1990). Unlike trazodone, nefazodone is active in several classical antidepressant screening tests such as reversal of reserpine-induced ptosis (Eison et al. 1990). Moreover, nefazodone also exhibits all characteristics of antidepressant potential in mechanism-independent behavioral models such as learned helplessness and the differential reinforcement for low rates of response-72 $\mathrm{s}$ paradigm (DRL-72) (Eison et al. 1990). Nefazodone is devoid of anticholinergic activity, exhibits no cardiac toxicity, has no affinity for histamine receptors and has less affinity for $\alpha_{1}$-adrenergic receptors compared to most other antidepressants, and in particular trazodone.

Therefore, the preclinical profile of nefazodone suggested that it may be a more effective antidepressant than trazodone with a lower incidence of sedation, hypotension, and other adverse events mediated through $\alpha$-adrenergic blockade. The antidepressant efficacy of nefazodone has already been demonstrated as superior to placebo or equivalent to imipramine in several US studies among major depressive outpatients (Feighner et al. 1989; D'Amico et al. 1990). The purpose of the present trial was to confirm the antidepressant potential of nefazodone in 
major depressive inpatients. As will be discussed, we felt that depressive inpatients represent a particular subgroup more suitable to demonstrate differences in the clinical activity of antidepressants (Ansseau 1992).

\section{Materials and methods}

Design of the study. The study was performed between December 1989 and April 1991 in ten Belgian centers used to collaborating (Ansseau et al. 1989a, b, 1991b) and exhibiting excellent reliability in clinical ratings (see affiliations). The number of patients enrolled at each site ranged from 5 to 24 with a median of 11 inclusions. The trial used a double-blind design with two parallel groups of patients randomly assigned to flexible doses of nefazodone or amitriptyline. After an initial dose of nefazodone $100 \mathrm{mg}$ or amitriptyline $50 \mathrm{mg}$ at bedtime for the first 2 days, the dosage was titrated between 100 and $300 \mathrm{mg}$ for nefazodone and between 50 and $150 \mathrm{mg}$ for amitriptyline during the first 3 weeks and between 100 and $400 \mathrm{mg}$ for nefazodone and 50 and $200 \mathrm{mg}$ for amitriptyline for the subsequent 3 weeks. The dosages were determined by the investigator on the basis of the clinical response and the adverse experience profile of each patient.

Due to a general impression of the investigators of low overall therapeutic efficacy, an interim analysis was performed using the data of 69 patients who had completed the study. This analysis revealed $61 \%$ of treatment responders, as defined by a rating of much or very much improved on the clinical global impressions (CGI) (Guy 1976). Nonresponders were characterized by lower daily dosage than responders during the first 2 weeks of treatment: 3.5 versus 3.67 tablets during week 1 and 3.89 versus 4.29 during week 2 . Therefore, an amendment was adopted for the remaining patients ( $26 \%$ of the sample) which specified that the daily doses were $200 \mathrm{mg}$ for nefazodone and $100 \mathrm{mg}$ for amitriptyline during week 1 , between 100 and $400 \mathrm{mg}$ for nefazodone and 50 and $200 \mathrm{mg}$ for amitriptyline during week 2 , and between 200 and $400 \mathrm{mg}$ for nefazodone and 100 and $200 \mathrm{mg}$ for amitriptyline during the following 4 weeks.

The study drugs were presented as nefazodone $50 \mathrm{mg}$ or amitriptyline $25 \mathrm{mg}$ tablets and administered in two daily intakes, morning and evening, until a maximal daily dose of nefazodone $300 \mathrm{mg}$ or amitriptyline $150 \mathrm{mg}$, and in three daily intakes, morning, noon, and evening for higher doses. Compliance was controlled by drug count; plasma monitoring was not performed. The active period was preceded by a drug-free period of 4 days to 4 weeks. No other psychotropic mediation was taken, except for occasional lormetazepam at a low dose as hypnotic. Moreover, other therapeutic interventions (e.g., formal psychotherapy) were not allowed during the trial. The duration of the study was 6 weeks, with assessments at baseline and after $1,2,3,4$, and 6 weeks of treatment. The trial was monitored according to all principles of European and US good clinical practice (Ministère de Affaires Sociales et de l'Emploi 1987; Mathieu 1990).

Subjects. A total of 106 inpatients were included in the study: 55 in the nefazodone group and 51 in the amitriptyline group. Patients were 32 men and 74 women, aged $24-79$ years, with a mean age (SD) of 47.2 (13.4) years. All subjects were depressed inpatients who fulfilled DSM-III-R criteria for moderate or severe major depression (99 patients) or bipolar disorder, depressed ( 7 patients) (American Psychiatric Association 1987) and had a score of at least 27 on the Montgomery and Asberg depression rating scale (MADRS) (Montgomery and Asberg 1979). Fifty-nine (56\%) patients also met DSMIII-R criteria for melancholia. Patients presenting any evidence of contraindications for a tricyclic antidepressant, or serious or uncontrolled medical ilness, were excluded from the study. The demographic and clinical characteristics of the patients are presented in Table 1. No statistically significant differences existed between the treatment groups.

All patients remained hospitalized for at least the screening phase and the first 2 weeks of treatment. The protocol obtained the approval of the Ethical Committee of the University of Liège Medi- cal School and all patients were fully informed of the purpose of the study and gave their consent.

Assessments. The MADRS, the CGI, and the Patient Global Assessment (PGA) (Guy 1976) were completed at baseline and after 1, 2, 3, 4 , and 6 weeks of treatment. Vital signs and all adverse experiences were also recorded at the same times. The 17-item Hamilton depression scale (Hamilton 1960) was completed at baseline as well as after 4 and 6 weeks of treatment. EKGs and laboratory tests, including hepatic and renal balance sheets, were carried out before treatment and after 2 and 6 weeks of therapy, while a thorough physical examination was performed before and at the end of the treatment period.

Data analysis. A one-way analysis of variance (ANOVA) with treatment as main effect was used for test for baseline comparability as well as differences between treatments for the change from baseline in MADRS scores, Hamilton depression total and factor scores, as defined by the ECDEU (Guy 1976), and CGI level of severity. Categorical data such as dropout rate, level of side effects, and demographic characteristics, CGI global improvement, and PGA were analyzed with the Fisher's exact test and a responder/ nonresponder categorization, using a CGI rating of "much improved" or "very much improved" as definition of treatment response. The sample size of 106 patients had a power of $>80 \%$ to detect an average difference of 7 in the MADRS total score between nefazodone and amitriptyline. This sample size was based on the Student's two sample $t$-test with an alpha level of 0.05 . The error of variance (150) was estimated using data from previous efficacy studies. Analyses of the intent-to-treat sample were performed using the last observation carried forward (LOCF) as the primary data set and visit-wise data set as confirmatory data. Moreover, similar confirmatory analyses were performed on the standard efficacy sample which excluded patients who discontinued treatment within the first 2 weeks. Since the conclusions of the confirmatory analyses did not differ from the primary analyses, they will not be reported here. Finally, the issue of the treatment by center outcome was investigated by assessing the significance of adding a site effect and a site by treatment interaction to the statistical models used in the LOCF analyses. Computations were performed using the general linear model procedure of SAS version 5.18.

\section{Results}

\section{Dropouts}

A total of 38 patients $(35.8 \%$ ) did not complete the study: significantly more patients discontinued in the nefazodone treatment group ( 26 or $47 \%$ ) as compared to the amitriptyline treatment group $(12$ or $24 \%)(P=0.015)$. Main reasons for discontinuation from the study were lack of efficacy $(10$ or $18.2 \%$ in the nefazodone group and 4 or $7.8 \%$ in the amitriptyline group, $P=0.15$, NS) and adverse experience ( 7 or $12.7 \%$ in the nefazodone group and 2 or $3.9 \%$ in the amitriptyline group, $P=0.16$, NS). One patient in the nefazodone group committed suicide after 24 days of study treatment.

\section{Efficacy}

MADRS. The changes over time on the MADRS in the two groups are displayed in Fig. 1. Amitriptyline was significantly more effective than nefazodone $(F=21.63$, $d f=1,101, P=0.0001)$ with a trend already noted at week $1(P<0.1)$ and a significant superiority $(P<0.01)$ from week 2 . The centers did not differ in their outcome 
Table 1. Demographic and clinical characteristics of the sample

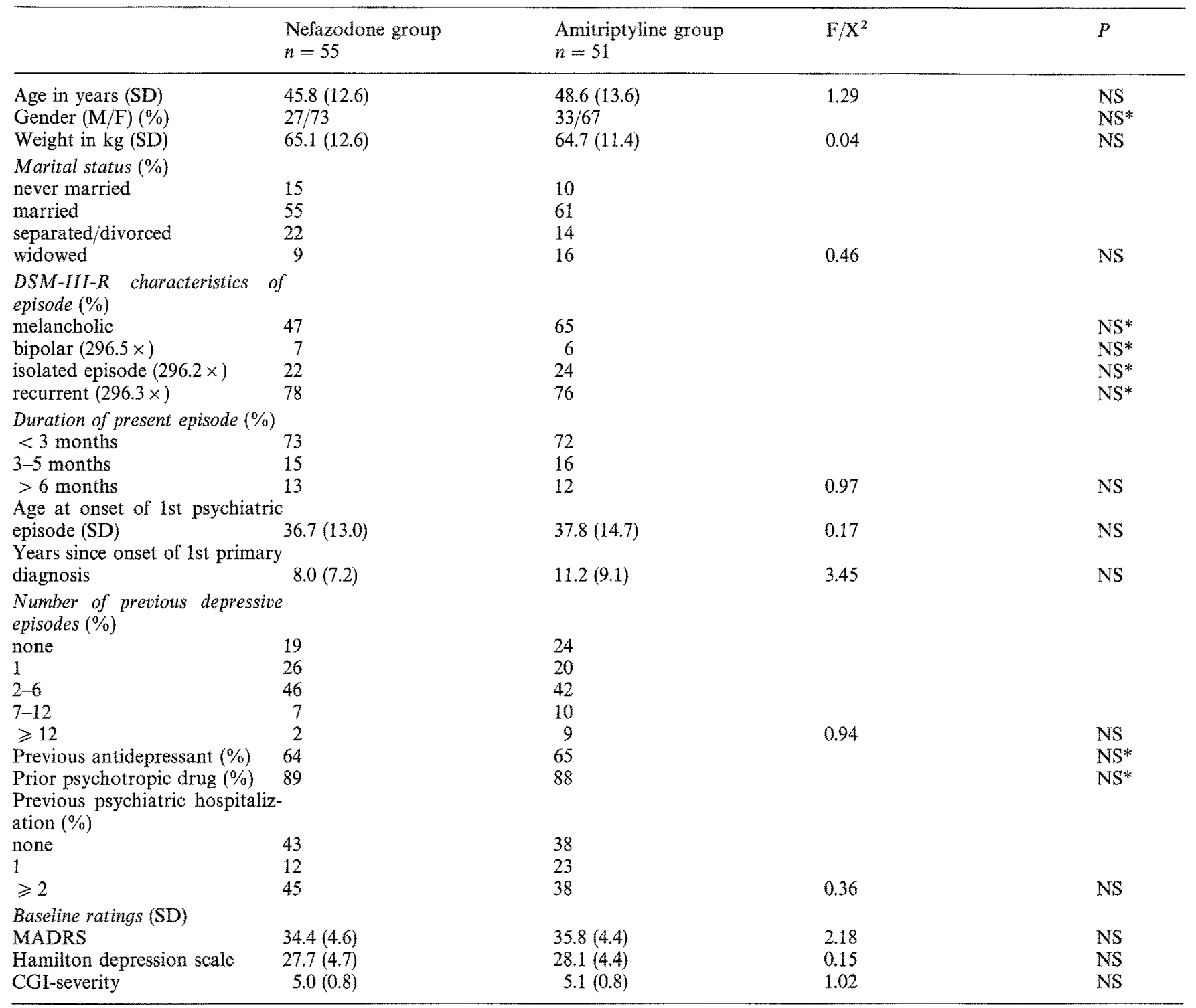

*Fisher's exact test

$(F=0.70, d f=9.82, P=0.70)$. The MADRS symptom profiles at baseline and at endpoint in the two treatment groups are displayed in Fig. 2.

Hamilton depression scale. The changes over time on the Hamilton depression scale in the two treatment groups are displayed in Fig. 3. Amitriptyline was significantly more effective than nefazodone $(F=12.97, d f=17,9$, $P=0.0006)$ with greater improvement after 4 and 6 weeks of treatment $(P<0.001)$. The centers did not differ in their outcome $(F=0.70, d f=8,61, P=0.70)$. The symptom profiles at baseline and at endpoint in the two treatment groups are displayed in Fig. 4. All three factors defined by Guy (1976) exhibited a better improvement with amitriptyline as compared to nefazodone: retardation after $4(P<0.05)$ and 6 weeks $(P<0.01)$ of treatment; anxiety/somatization after 4 and 6 weeks $(P<0.01)$; and sleep disturbance after $4(P<0.1)$ and 6 weeks $(P<0.05)$.
CGI. The changes over time on the CGI severity of illness in the two groups are displayed in Fig. 5. Amitriptyline was significantly more effective than nefazodone $(F=18.37, d f=1,101, P=0.0001)$, with a trend at week $2(P<0.1)$ and a significant superiority from week $3(P<0.01)$. The CGI global improvement showed significantly more responders to amitriptyline than to nefazodone at weeks 4 (31 or $63.2 \%$ versus 19 or $35.1 \%$, $P=0.01)$ and 6 (34 or $69.4 \%$ versus 21 or $38.8 \%$, $P=0.01)$.

PGA. A significantly greater percentage of patients treated with amitriptyline as compared to nefazodone rated themselves as "much improved" or "very much improved" i.e., as "responders", at weeks 3 (27 or $55.1 \%$ versus 18 or $33.3 \%, P<0.06), 4$ (31 or $63.2 \%$ versus 17 or $31.5 \%$, $P<0.01)$ and 6 (32 or $65.3 \%$ versus 16 or $29.6 \%$, $P<0.01$ ). 


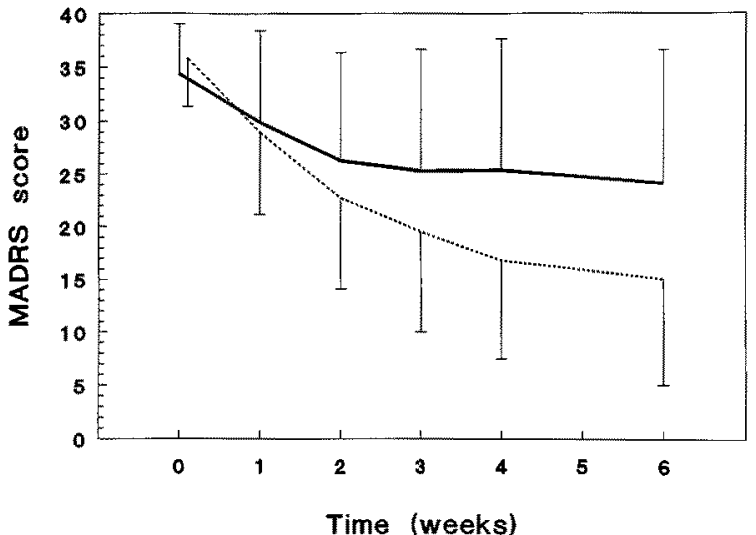

Fig. 1. Changes over time in mean scores $( \pm S D)$ on the MADRS among patients treated by nefazodone or amitriptyline. - - nefazodone; ...., amitriptyline
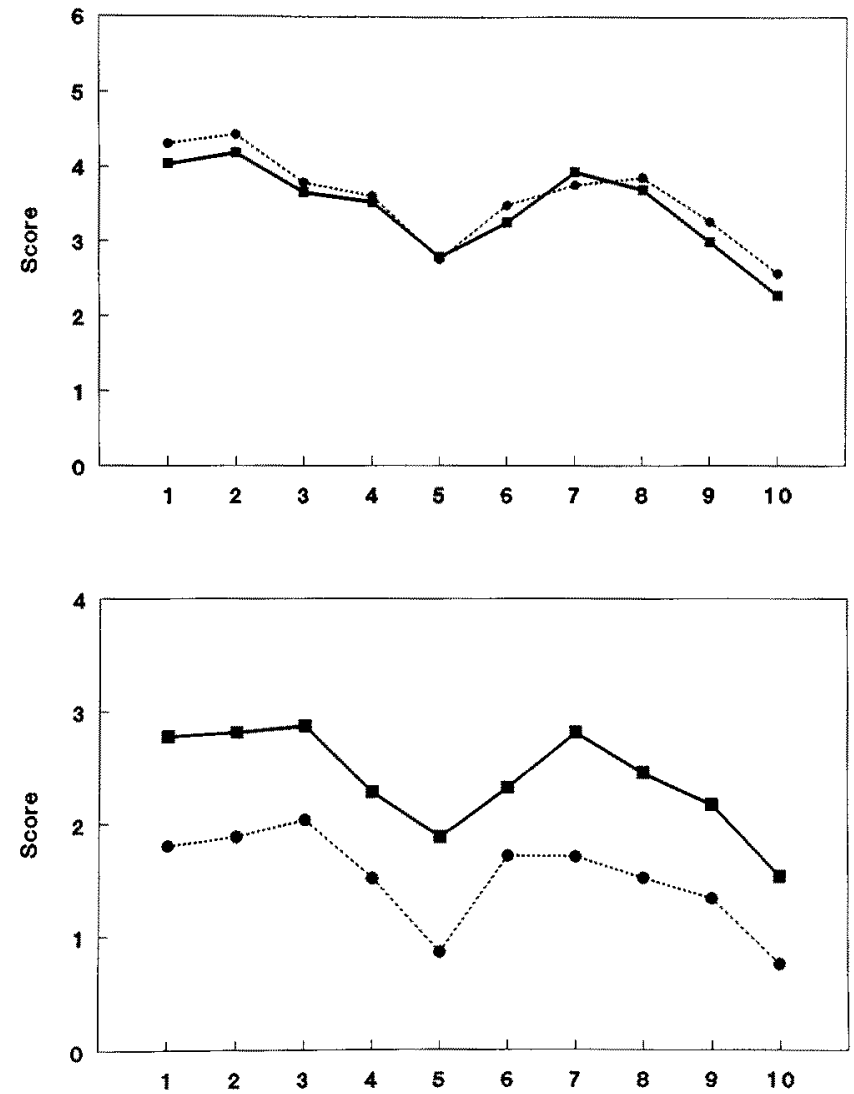

Fig. 2. Individual MADRS items: profile at baseline (upper part) and at endpoint (lower part) among patients treated with nefazodone or amitriptyline. MADRS items: 1, apparent sadness; 2, reported sadness; 3, inner tension; 4, reduced sleep; 5 , reduced appetite, 6 , concentration difficulties; 7 , lassitude; 8 , inability to feel; 9 , pessimistic thoughts; 10 , suicidal thoughts. - nefazodone; $\cdots \cdot \cdots$, amitriptyline

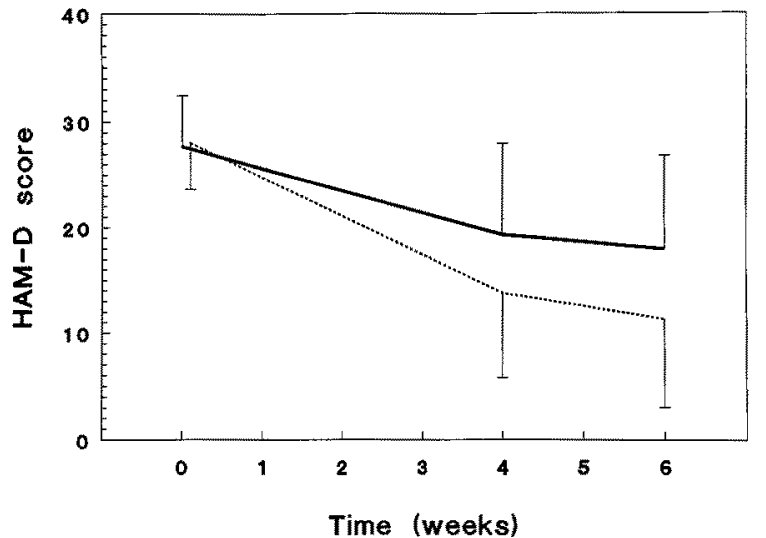

Fig. 3. Changes over time in mean scores $( \pm S D)$ on the Hamilton depression scale among patients treated by nefazodone or amitriptyline. —_, nefazodone; ..., amitriptyline
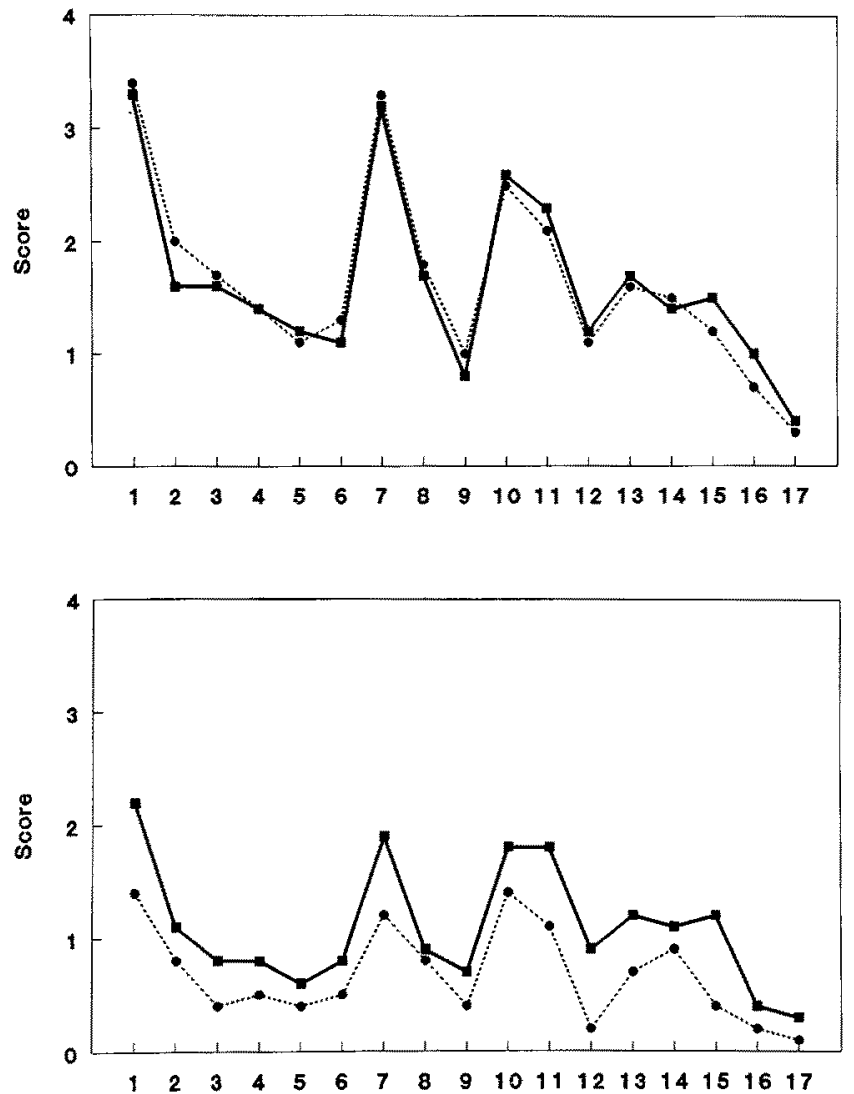

Fig. 4. Individual Hamilton depression scale items: profile at baseline (upper part) and at endpoint (lower part) among patients treated with nefazodone or amitriptyline. Hamilton depression scale items: 1 , depressed mood; 2, feeling of guilt; 3 , suicide; 4, initial insomnia; 5 , middle insomnia; 6 , delayed insomnia; 7 , work and interests; 8 , retardation; 9, agitation; 10, anxiety (psychological); 11 , anxiety (somatic); 12, somatic symptoms (gastrointestinal); 13, somatic symptoms (general); 14, loss of libido; 15, hypochondriasis; 16 , weight loss; 17, loss of insight. $-\mathbf{n}-$, nefazodone; $\cdots \bullet$, amitriptyline 


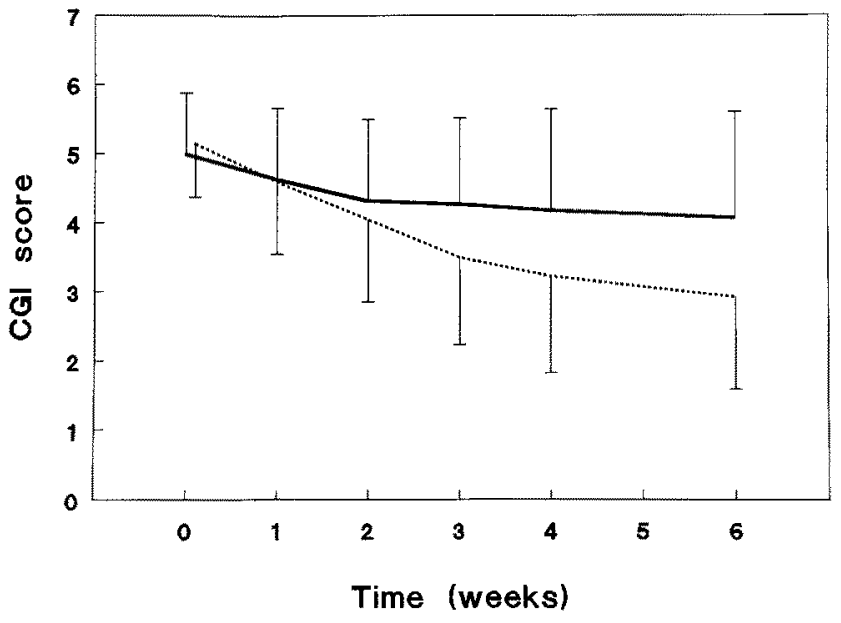

Fig. 5. Changes over time in mean scores ( $\pm S D$ ) on the CGI severity of illness among patients treated by nefazodone or amitriptyline. - nefazodone; ..., amitriptyline

\section{Safety}

The comparison of the frequency of side effects in the two treatment groups is presented in Table 2 . Dry mouth was significantly more often reported with amitriptyline than with nefazodone.

Physical examinations did not show any finding of medical importance. Blood pressure did not exhibit significant changes during the study and EKGs and laboratory tests did not reveal significant alterations.

\section{Dosage}

Mean nefazodone daily doses (SD) were $191.7 \mathrm{mg}(42.1)$ during week $1,218.9 \mathrm{mg}(60.6)$ during week $2,244.6 \mathrm{mg}$ (79.0) during week $3,266.2 \mathrm{mg}(81.7)$ during week 4 , and $242 \mathrm{mg}(86.5)$ at week 6; corresponding doses for amitriptyline were, respectively, $96.4 \mathrm{mg} \mathrm{(23.9),} 106.6 \mathrm{mg}(26.4)$, $119.4 \mathrm{mg}(34.1), 125.0 \mathrm{mg}(35.4)$, and $124.4 \mathrm{mg}$ (38.5). Mo- dal daily doses within the last treatment week increased significantly in the 27 patients included after the protocol mendment as compared to the 79 previous ones $(F=3.85$, $d f=1,99, P=0.05$ ); this increase was however only statistically significant in the nefazodone group: from 225.0 to $296.4 \mathrm{mg}(P<0.001)$ and not in the amitriptyline group: from 116.7 to $132.7 \mathrm{mg}$.

\section{Discussion}

The results of the present study show that nefazodone at a final modal daily dose of $242 \mathrm{mg}$ is significantly less effective than amitriptyline at a final modal daily dose of $124 \mathrm{mg}$ in major depressive inpatients. Indeed, all rating instruments favor amitriptyline over nefazodone: MADRS, Hamilton depression scale including retardation, anxiety, and sleep disturbance factors, CGI, and PGA. Moreover, the conclusions from the analysis of the visit-wise data set are not different from the intent-to-treat (LOCF) analysis, a surprising finding considering the large number of dropouts, particularly in the nefazodone group, which demonstrates that not only was nefazodone responsible for more dropout for inefficacy but that it was also much less effective than amitriptyline in the patients who completed the 6-week trial. These findings contradict US trials where nefazodone was found significantly more effective than placebo and equivalent to imipramine (Feighner et al. 1989; D'Amico et al. 1990).

These discrepancies could be explained in two ways. First, the dosage of nefazodone in the present study could have been selected below the optimal therapeutic dose. Supporting this hypothesis, a recent study by Fontaine et al. (1991) comparing low-dose nefazodone (final modal daily dose $=246 \mathrm{mg}$ ), high-dose nefazodone (final modal daily dose $=462 \mathrm{mg}$ ), imipramine (final modal daily dose $=216 \mathrm{mg}$ ), and placebo in depressive outpatients found no significant differences in efficacy between lowdose nefazodone and placebo, whereas high-dose nefazodone was more effective than placebo and equivalent to imipramine. It should be noted that the nefazodone modal daily "low dose" in Fontaine's study was quite
Table 2. Comparison of the frequency of adverse events $(\%)$

\begin{tabular}{|c|c|c|c|}
\hline & $\begin{array}{l}\text { Nefazodone group } \\
n=55\end{array}$ & $\begin{array}{l}\text { Amitriptyline group } \\
n=51\end{array}$ & $p^{*}$ \\
\hline \multicolumn{4}{|l|}{ Body as a whole } \\
\hline headache & 9.1 & 2.0 & NS \\
\hline abdominal pain & 5.5 & 0 & NS \\
\hline \multicolumn{4}{|l|}{ Digestive system } \\
\hline nausea & 14.6 & 7.8 & NS \\
\hline dry mouth & 10.9 & 39.2 & 0.001 \\
\hline constipation & 9.1 & 11.8 & NS \\
\hline dyspepsia & 1.8 & 5.9 & NS \\
\hline vomiting & 5.5 & 0 & NS \\
\hline \multicolumn{4}{|l|}{ Nervous system } \\
\hline attention decreases & 7.3 & 3.9 & NS \\
\hline tremor & 5.5 & 11.8 & NS \\
\hline insomnia & 5.5 & 3.9 & NS \\
\hline
\end{tabular}

*Fischer's exact test 
similar to the nefazodone dose used in our trial: respectively, 246 and $242 \mathrm{mg}$. The selection of the nefazodone dose range for our study was based on a dose-ranging study comparing fixed doses of nefazodone $50,100,200$, and $300 \mathrm{mg}$ daily with placebo which demonstrated a significant efficacy for both the $100 \mathrm{mg}$ and $200 \mathrm{mg}$ doses but a lack of improvement in the $50 \mathrm{mg}$ and more unexpectedly in the $300 \mathrm{mg}$ groups (D'Amico et al. 1990).

An alternative explanation in these discrepancies regarding nefazodone efficacy between our trial and the previous published reports is that patients included in European studies greatly differ from US patients in terms of type of recruitment, severity, symptom profile, presence of endogenous features, socio-economic origin, family, social, and professional adjustment, personality disturbances (Ansseau 1992) and could respond less to atypical antidepressants. For example, in our study, mean 17-item Hamilton depression scores were 27.8 for DSM-II-R nonmelancholic major depressive patients and 28.3 for melancholic patients; in comparison, the mean Hamilton rating of US patients involved in similar comparative studies of nefazodone was 23.6 for nonmelancholic major depressive patients $(n=838)$ and 25.0 for melancholic patients $(n=938)$ (von Frenckell et al. 1992). Yet caution is warranted in assuming actual differences in illness severity due to the lack of studies of interrater reliability between Europe and the US. Our personal experience in psychiatric departments both in the US and in Belgium, however, found a tendency to rate higher among US clinicians. Moreover, a recent comparison of scores on the individual 17 items of the Hamilton depression scale using the nefazodone database revealed 10 items significantly higher among the 473 European patients (depressed mood, suicide, delayed insomnia, work and interests, retardation, psychic anxiety, gastrointestinal symptoms, hypochondriasis, weight loss, and loss of insight) and 5 items with higher scores among the 1778 US patients (feeling of guilt, middle insomnia, somatic anxiety, general somatic symptoms, and loss of libido) (von Frenckell et al. 1992). A elegant method to resolve possible differences in rating between European and US psychiatrists could be the use of self-rating scales. Unfortunately, none of them was included in the current protocol. It should be noted, however, that they are very often difficult to complete for severely depressed inpatients; moreover, their sensitivity to clinical changes is generally lower than observers' rating scales (Bobon 1987).

Studies involving hospitalized depressive patients are also much more common in Europe. Depressive inpatients tend to be much more homogeneous, display high level of severity, endogenous features, and suicidal ideation (von Frenckell et al. 1992). They are less responsive to placebos, benzodiazepines, and more importantly to "minor" antidepressants (Ansseau 1992). Indeed, during the 1970 s, a number of compounds chemically and pharmacologically different from the tricyclics have been proposed as antidepressants. Although several of these compounds, such as viloxazine, mianserine, or trazodone, have been in general use for some years, their clinical efficacy has been seriously questioned, mainly on the basis of analyses of the clinical trials (Kragh-Sorensen et al. 1983). In our study, $65 \%$ of the patients were resistant to previous antidepress- ants whereas most US studies include drug-naive patients. Depressive inpatients appear therefore particularly suited for testing the antidepressant potential of new compounds (Ansseau et al. 1991).

Interestingly, several European studies of new antidepressant drugs found an efficacy lower than reference tricyclics in hospitalized patients. As examples, three independent trials conducted by the Danish University Antidepressant Group found the selective 5-HT reuptake inhibitors citalopram and paroxetine as well as the reversible MAO-A inhibitor moclobemide weaker antidepressants than clomipramine (Danish University Antidepressant Group 1986, 1990, 1993). These results also contrast the majority of studies on citalopram, paroxetine, and moclobemide (Dechant and Clissold 1991; Milne and Goa 1991; Fitton et al. 1992). When analysing the differences in outcome between their studies and the literature on these new antidepressants, the authors raise the possibility of differences in patient populations, rating methodology, spontaneous recovery, dosing, trial quality, and sample size (Danish University Antideperssant Group 1993). The only demonstrated difference, however, is that the studies performed by the Danish University Antidepressant Group differ from the vast majority in the field by only including hospitalized patients which may represent a different type of depression (Danish University Antidepressant Group 1993). The authors advocate a strong need for revised standards for the conduction of clinical trials with antidepressants, including a more detailed account on patient recruitment and background variables and tightening up of several methodological facets (Danish University Antidepressant Group 1993). Our present study confirms that such methodology may eventually lead to more conclusive efficacy studies on antidepressants. The differences in the selection process and in the clinical characteristics of the patients might explain the contradictory results obtained in our study and in US trials.

Several limitations in the design in the present study should be acknowledged and discussed. First, the lack of a placebo-treated group makes it necessary to interpret very cautiously all data concerning efficacy. A placebo arm would have enabled us to assess whether nefazodone exhibits any effect in this patient sample as opposed to results in earlier studies. Second, an amendment changes the titration schedule of the study in the last quarter of patients included. This amendment was based on an blind interim analysis of the 69 first patients showing a rather low overall response $(61 \%)$, possibly related to lower dosage during the first 2 weeks in the nonresponders. The global response rate did not improve, however, after this amendment, reaching only $53 \%$ for the whole sample. This global rate results from very different responses in the two groups: $39 \%$ with nefazodone and $69 \%$ with amitriptyline. Third, the inclusion of elderly depressive patients can be criticized, particularly in view of the age-related modifications of nefazodone pharmacokinetics. It should be noted, however, that the dose of nefazodone was individually adapted and considered to the optimal for each patient. Moreover, until now, the efficacy and tolerability of nefazodone have never been specifically assessed in elderly depressive patients. Fourth, the use of flexible 
dosage is another problem which should be emphasized. The titration of the dose on the basis of the clinical response and the adverse experience profile of each patient can in many ways seem irrelevant. Indeed, adverse events can appear on subtherapeutic doses of tricyclic antidepressants and the therapeutic effect is delayed by up to 4-6 weeks (Gram 1990).

In our study, the tolerance of nefazodone was better than amitriptyline with regard to anticholinergic side effects, particularly dry mouth. These findings confirm the previous trials which showed a much lower incidence of adverse events as compared to imipramine (Feighner et al. 1989; Fontaine 1992). Interestingly, the level of digestive adverse events associated with nefazodone in our study was very low, what clearly distinguishes nefazodone from selective 5-HT reuptake blockers such as fluoxetine (Benfield et al. 1986).

In conclusion, the present study suggests lower efficacy but better tolerance of nefazodone as compared to a reference tricyclic. The reasons for this lower efficacy as compared to previous trials, either due to a dose below the optimal range or to particular characteristics of European patients, should be carefully evaluated in further trials.

Acknowledgements. The authors would like to thank Drs. C. Vogels (Universiteit Ziekenhuis, Gent), P. Squelart, and A. Mercier (Hôpital Vésale, Montigny-le-Tilleul), P. Van Cauwenberghe (Psychiatrische Centra Sleidinge, Evergem), W. Pitchot (C.H.U. du Sart Tilman, Liège), C. Simon (Hôpital du Petit Bourgogne, Liège), M.A. GérardVandenhove (Hôpital de la Citadelle, Liège), J.L. Cerfontaine (Clinique Saint-Vincent, Rocourt), J. Raemdonck (Sint-Camillus Hospital, Sint-Denijs-Westrem), who participated in the study; and $\mathrm{Ch}$. Gayetot, for her secretarial assistance.

\section{References}

American Psychiatric Association (1987) Diagnostic and statistical manual of mental disorders, 3rd ed (revised). Washington, DC

Andrade R, Nicoll RF (1987) Pharmacologically distinct actions of serotonin on single pyramidal neurones of the rat hippocampus recorded in vitro. J Physiol 394:99-124

Ansseau M (1992) The Atlantic gap: clinical trials in Europe and the United States. Biol Psychiatry 31:109-111

Ansseau M, von Frenckell R, Mertens C, De Wilde J, Botte L, Devoitille JM, Evrard JL, De Nayer A, Darimont P, Dejaiffe G, Mirel J, Meurice E, Parent M, Couzinier JP, Demarez JP, Serre $C$ (1989a) Controlled comparison of two doses of milnacipran (F 2207) and amitriptyline in major depressive inpatients. Psychopharmacology $98: 163-168$

Ansseau M, von Frenckell R, Papart P, Mertens C, De Wilde J, Botte L, Devoitille JM, Evrard JL, De Nayer A, Koch-Bourdouxhe S, Darimont P, Lecoq A, Mirel J, Couzinier IP, Demarez JP, Serre C (1989b) Controlled comparison of milnacipram (F2207) $200 \mathrm{mg}$ and amitriptyline in endogenous depressive inpatients. Hum Psychopharmacol 4:221-227

Ansseau M, Devoitille JM, Papart $\mathbf{P}$, Vanbrabant E, Mantanus $H$, Timsit-Berthier M (1991a) Comparison of adinazolam, amitriptyline, and diazepam in endogenous depressive inpatients exhibiting DST nonsuppression or abnormal contingent negative variation. J Clin Psychopharmacol 11:160-165

Ansseau M, yon Frenckell R, Gérard MA, Mertens C, De Wilde J, Botte L, Devoitille JM, Evrard JL, De Nayer A, Darimont P, Mirel J, Troisfontaines B, Toussaint C, Couzinier JP, Demarez JP, Serre C (1991b) Interest of a loading dose of milnacipran in endogenous depressive inpatients: comparison with the standard regimen and with fluvoxamine. Eur Neuropsychopharmacol $1: 113-121$

Benfield P, Heel RC, Lewis SP (1986) Fluoxetine: a review of its pharmacodynamic and pharmacokinetic properties, and therapeutic efficacy in depressive illness. Drugs $32: 481-508$

Bobon D (1987) Us et abus des échelles d'évaluation en psychopathologie. Psychiat-Psychobiol 2:379-385

D'Amico MF, Roberts DL, Robinson DS, Schwiderski UE, Copp J (1990) Placebo-controlled dose-ranging trial designs in phase II development of nefazodone. Psychopharmacol Bull 26 [1]: $147-150$

Danish University Antidepressant Group (1986) Citalopram: clinical effect profile in comparison with clomipramine. A controlled multicenter study. Psychopharmacology 90:131-138

Danish University Antidepressant Group (1990) Paroxetine; a selective serotonin reuptake inhibitor showing better tolerance, but weaker antidepressant effect than clomipramine in a controlled multicenter study. J Affect Disord 18:289-299

Danish University Antidepressant Group (1993) Moclobemide: a reversible MAO-A-inhibitor showing weaker antidepressant effect than clomipramine in a controlled multicenter study. J Affect Disord 28:105-116

Dechant KL, Clissold S (1991) Paroxetine: a review of its pharmacodynamic and pharmacokinetic properties and therapeutic potential in depressive illness. Drugs $41: 225-253$

Eison AS, Eison MS, Torrente JR, Wright RN, Yocca FS (1990) Nefazodone: preclinical pharmacology of a new antidepressant. Psychopharmacol Bull 26 [3]:311-315

Feighner JP, Pambakian R, Fowler RC, Boyer WF, D'Amico MF (1989) A comparison of nefazodone, imipramine, and placebo in patients with moderate to severe depression. Psychopharmacol Bull 25 [2]: 219-221

Fitton A, Faulds D, Goa KL (1992) Moclobemide. A review of its pharmacological properties and therapeutic use in depressive illness. Drugs 43:561-596

Fontaine R (1992) Novel serotonergic mechanisms and clinical experience with nefazodone. Clin Neuropharmacol 15 [suppl 1]: $99 \mathrm{~A}$

Fontaine R, Ontiveros A, Faludi G, Elie R, Roberts D, Ecker J (1991) A study of nefazodone, imipramine, and placebo in depressed outpatients. Biol Psychiatry 29:364S

Gam LF (1990) Inadequate dosing and pharmacokinetic variability as confounding factors in assessment of efficacy of antidepressants. Clin Neuropharmacol 13 [Suppl 1]:35-44

Guy W (ed) (1976) ECDEU Assessment manual for psychopharmacology (revised). National Institute of Mental Health, Psychopharmacology Research Branch, Rockville, Md.

Hamilton M (1960) A rating scale for depression. J Neurol Neurosurg Psychiatry 12:56-62

Kragh-Sorensen P, Christensen P, Gram LF, Kristensen CB, Pedersen OL (1983) Phase-4 studies in psychopharmacology. New antidepressants. In: Gram LF et al. (eds) Clinical pharmacology in psychiatry. Bridging the experimental therapeutic gap. MacMillan, London, pp 114-125

Mathieu M (1990) New drug development: a regulatory overview. Parexel, Cambridge, Mass.

Milne RJ, Goa KL (1991) Citalopram: a review of its pharmacodynamic and pharmacokinetic properties, and therapeutic potential in depressive illness. Drugs 41:450-477

Ministère des Affaires Sociales et de l'Emploi, Ministère chargé de la Santé et de la Famille, Direction de la Pharmacie et du Médicament (1987) Bonnes pratiques cliniques. Avis aux promoteurs et aux investigateurs pour les essais cliniques des médicaments. Texte officiel en langue française. Paris, France

Montgomery A, Asberg M (1979) A new depression scale designed to be sensitive to change. Br J Psychiatry 134:382-389

von Frenckell R, Cheuvart B, Gratton R, Copp J, Gammans R, Vanbrabant E (1992) Clinical trials of antidepressants in the US and in Europe. The Atlantic gap. Clin Neuropharmacol 15 [suppl 1]:516B 